\title{
Considerações sobre a eficiência de misturas de concreto de cimento Portland com base no conceito de empacotamento de partículas
}

\author{
Considerations on the efficiency of \\ Portland cement concrete mixtures \\ based on the particle packing \\ concept
}

Herbert Medeiros Torres Lopes ${ }^{1}$, Ana Carolina Corsi Peçanha ${ }^{1}$, Alessandra Lorenzetti de Castro ${ }^{1}$

\author{
${ }^{1}$ Departamento de Engenharia de Estruturas, Escola de Engenharia de São Carlos, Universidade de São Paulo - Av. Tra- \\ balhador Sancarlense, 400, Centro, CEP 13566-590, São Carlos, SP, Brasil. \\ e-mail: herbert_lopes@usp.br, ana.pecanha@usp.br, alcastro@sc.usp.br
}

\section{RESUMO}

O concreto é o material de construção mais utilizado e nos últimos anos, estudos têm sido desenvolvidos em busca de materiais com desempenho mecânico e durabilidade superior. Com a finalidade de abranger a realidade das obras civis no que se refere à produção in loco do concreto convencional e de alta resistência, diversos métodos de dosagem são propostos. Apesar de esses métodos permitirem obter a proporção ideal entre os materiais constituintes da mistura de concreto, é possível otimizar a composição aplicando-se o conceito de empacotamento de partículas. Diante disso, o presente estudo tem por objetivo avaliar a eficiência do empacotamento de partículas de misturas de concretos de cimento Portland amplamente utilizados na prática da construção civil, obtidas por métodos de dosagem tradicionais. Para isso, foram produzidos três traços de concreto utilizando o método de dosagem tradicional IPT/EPUSP, sendo dois para concretos com classe de resistência convencional e um de alta resistência. Conhecendo a proporção e a distribuição granulométrica dos materiais constituintes desses concretos, o coeficiente de distribuição de cada mistura foi determinado considerando o modelo de empacotamento de Alfred. Posteriormente, mantendo-se o mesmo coeficiente de distribuição, as misturas de concretos foram otimizadas aplicando o conceito de empacotamento de partículas, sendo determinadas as propriedades físicas e mecânicas dos concretos. No processo de otimização, verificouse lacunas entre as distribuições granulométricas dos materiais constituintes normalmente considerados na produção dos concretos, caracterizando uma deficiência quanto ao empacotamento. Com relação as propriedades do concreto no estado endurecido, as misturas otimizadas apresentaram, em geral, propriedades físicas e mecânicas superiores aos concretos de referência.

Palavras-chave: Concreto, Método de dosagem, Empacotamento de partículas, Modelo de Alfred, Coeficiente de distribuição.

\begin{abstract}
Concrete is the most widely used building material and, recently, studies have been developed in pursuit of materials with superior mechanical performance and durability. In order to cover the reality of the civil works regarding the on-site production of conventional and high strength concrete, several mix design methods are proposed. Although these methods allow obtaining the ideal proportion between the constituent materials of the mixture, it is possible to optimize the composition by applying the concept of particle packing. Therefore, this paper aims to measure the efficiency of the particle packing of Portland cement concrete mixtures widely used in civil construction's practice, obtained by traditional mix design methods. For this, three concrete mixtures were produced using the traditional IPT/EPUSP mix design method, being two of conventional strength and one of high strength. By knowing the proportion and particle size distribution of the constituent materials of these concretes, the distribution's coefficient of each mixture was determined considering Alfred's particle
\end{abstract}


packing model. Thereafter, maintaining the same distribution coefficient, the concrete mixtures were optimized by applying the particle packing concept, determining the physical and mechanical properties of the concrete. During the optimization process, there were gaps between the particle size distributions of the component materials normally considered in the production of concretes, characterizing a lack in packaging. Regarding the properties of the hardened concrete, the optimized mix design generally presented superior physical and mechanical properties than the reference concrete.

Keywords: concrete, mix design method, particle packing, Alfred's model, distribution coefficient.

\section{INTRODUÇÃO}

A construção civil é considerada uma das principais atividades econômicas de um país, sendo responsável por um grande consumo de energia e extração de recursos naturais. O principal insumo deste setor é o concreto de cimento Portland, sendo considerado o material de construção mais consumido em escala mundial, e em relação aos materiais de consumo, é visto como o segundo mais desfrutado, ficando apenas atrás da água [1]. Sua preferência em relação a outros materiais de construção justifica-se por ser um material de fácil moldagem, que possibilita a execução em diversas formas e tamanhos, além de apresentar boa resistência mecânica após endurecido (similar a rochas naturais) e ser economicamente atrativo. Dessa forma, é possível observar a aplicação desse material em diversas obras de engenharia, tais como: pontes, edificações, usinas hidrelétricas, pavimentação, túneis, estruturas de contenção, dentre outras.

Com o desenvolvimento das obras de engenharia, os profissionais responsáveis pelo aperfeiçoamento da tecnologia do concreto, pressionadas pela exigência do mercado, têm investigado novas metodologias para aprimorar as propriedades desse material. Para atender esses requisitos surge o conceito de empacotamento de partículas, o qual é aplicado em diversas áreas da engenharia, principalmente, naquelas que exigem um maior grau tecnológico para produzir materiais com elevado desempenho. Apesar dos diversos métodos de empacotamento abordados na literatura capazes de melhorar a ecoeficiência do concreto, atualmente há pouca ou quase nenhuma discursão sobre a interação entre o conceito de empacotamento de partículas, o comportamento reológico e o desempenho mecânico de misturas de concreto [2]. Na construção civil, o conceito de empacotamento de partículas é aplicado principalmente para concretos de resistência superiores. Porém, em concretos convencionais é menos explorada, mesmo sendo possível obter vantagens semelhantes àquelas obtidas para os concretos especiais, ainda que proporcionalmente inferiores.

\subsection{Método de dosagem tradicional}

O concreto é um material heterogêneo e de comportamento complexo, tanto no estado fresco quanto no estado endurecido. Diante disso, a dosagem desse material torna-se uma tarefa bastante importante e desafiadora para os profissionais responsáveis por esta atividade, visto que a dosagem do concreto consiste na determinação da proporção ideal dos materiais constituintes (cimento, agregado graúdo, agregado miúdo, água e, em alguns casos, aditivos e adições), de maneira a produzir uma mistura tecnicamente adequada e economicamente viável.

Atualmente no Brasil ainda não existe um texto consensual de como deve ser realizado o estudo de dosagem de concreto de cimento Portland. Por não existirem diretrizes normativas específicas sobre os procedimentos e parâmetros de dosagem, vários pesquisadores apresentam seus métodos próprios de dosagem, que são desenvolvidos por institutos de pesquisas nacionais ou por adaptação de normas estrangeiras [3,4].

Assim ocorreu com o método da ABCP (Associação Brasileira de Cimento Portland), proposto inicialmente por Ary Torres e Carlos Rosman (1956), que atualmente adota uma adaptação do método americano do ACI (American Concrete Institute). Tal método fundamenta-se em tabelas e gráficos elaborados a partir de valores médios de resultados experimentais, sendo uma ferramenta adequada para a dosagem de concretos convencionais. Abordagem semelhante é feita com o método de dosagem IPT/EPUSP, que leva este nome por ter sido desenvolvido por pesquisadores do Instituto de Pesquisas Tecnológicas do Estado de São Paulo (IPT) e da Escola Politécnica da Universidade de São Paulo (EPUSP), método consagrado na literatura técnica desde a década de 1970 [5].

A partir do método de dosagem IPT/EPUSP obtém-se um diagrama de dosagem que somente é válido para o mesmo tipo e classe de cimento, adições minerais, agregados, mesmos equipamentos e manutenção das demais variabilidades e materiais sob controle. Qualquer modificação dos parâmetros selecionados inicialmente implica na necessidade de um novo estudo de dosagem. A partir deste diagrama - que relaciona, esquematicamente, a resistência à compressão, relação água/cimento, relação agregados secos totais/cimento 
e consumo de cimento - torna-se possível obter concretos com propriedades distintas e bem definidas em seu estado endurecido. Entretanto, o método apresenta alguns limites de aplicação [3], a saber:

- Resistência à compressão: $5 \mathrm{MPa} \leq \mathrm{f}_{\mathrm{c}} \leq 150 \mathrm{MPa}$;

- Relação água/cimento $(\mathrm{a} / \mathrm{c}): 0,15 \leq \mathrm{a} / \mathrm{c} \leq 1,50$;

- Abatimento: $0 \mathrm{~mm} \leq$ abatimento $\leq$ autoadensável;

- Dimensão máxima do agregado graúdo: $4,8 \mathrm{~mm} \leq \mathrm{D}_{\operatorname{máx}} \leq 100 \mathrm{~mm}$;

- Teor de argamassa seca: $30 \%<\alpha<90 \%$;

- Relação de água/materiais secos $(\mathrm{H}): 5 \%<\mathrm{H}<12 \%$;

- Módulo de finura do agregado: qualquer;

- Distribuição granulométrica dos agregados: qualquer;

- Massa específica do concreto: maior que $1500 \mathrm{~kg} / \mathrm{m}^{3}$.

Esse método, primeiramente, realiza um ajuste experimental das proporções dos materiais constituintes do concreto, objetivando determinar o teor ideal de argamassa. É importante ressaltar que a definição de um teor ideal de argamassa se deve aos problemas acarretados pela sua falta ou excesso: a falta de argamassa na mistura resulta em porosidade no concreto ou falhas de concretagem, enquanto seu excesso proporciona um concreto de melhor aparência, mas com maior custo por metro cúbico e risco de fissuração por origem térmica e por retração de secagem [6].

Definido o teor ideal de argamassa, o método de dosagem IPT/EPUSP envolve a determinação de três traços, sendo um pobre $(1: \mathrm{m}+1,5)$, um médio $(1: \mathrm{m})$ e um rico $(1: \mathrm{m}-1,5)$, que devem atender à mesma faixa de abatimento e manter o teor de argamassa ideal definido. Para os três traços são moldados corpos de prova, que são submetidos à cura úmida e ensaiados nas idades estabelecidas, de forma a determinar suas propriedades mecânicas no estado endurecido. A quantidade mínima de três misturas de concreto permite um ajuste das equações de correlação de dosagem, possibilitando a construção do diagrama de dosagem, no qual, por regressão linear, pode-se lograr qualquer resistência à compressão dentro do intervalo estudado para traços de uma mesma família.

Apesar dos métodos de dosagem tradicionais diferirem entre si, eles foram concebidos inicialmente para concretos de classe de resistência convencional, ou seja, sem qualquer característica especial. Porém, com o desenvolvimento da construção civil, juntamente com a engenharia de estruturas, surgiu a necessidade de utilizar concretos especiais, empregados por apresentarem características específicas, para atender às demandas das obras em que concretos convencionais não poderiam ser aplicados. Esse fato já vem sendo observado no concreto há anos, cuja resistência tem aumentado de forma contínua, preponderantemente na última década [3]. Isso deve-se também à evolução da tecnologia dos materiais constituintes, principalmente do cimento Portland, adições minerais e aditivos químicos, que possibilitam ao concreto atingir melhores desempenhos físicos e mecânicos, além de outros requisitos necessários para obras correntes como a redução da seção transversal dos elementos estruturais, economia de materiais, maior durabilidade que prolonga a vida útil das estruturas e, consequentemente, redução dos custos com manutenção. Assim, os profissionais que idealizaram tais métodos de dosagem tradicionais tiveram que adaptar uma metodologia auxiliar a fim de atender a essa nova demanda, implementando no próprio método de dosagem concebido inicialmente.

Os métodos de dosagem clássicos amplamente aplicados na indústria nacional da construção civil apresentam algumas limitações. O método de dosagem da $\mathrm{ABCP}$ possui como desvantagem o fato que os valores, a partir dos quais é realizado o proporcionamento dos materiais, são todos tabelados. Tais dados são limitados, portanto não abrangem todos os tipos de materiais existentes, o que conduz a uma única misturaresposta que, se não atender, exigirá, necessariamente, um novo estudo experimental. Por sua vez, o método de dosagem IPT/EPUSP exige apenas um estudo experimental que dá origem a uma família cujas propriedades ficam explicitadas no diagrama de dosagem dispensando novos estudos experimentais para aqueles mesmos materiais constituintes. Entretanto, é necessária a validação do resultado proveniente do diagrama de dosagem, sendo este resultado preponderantemente depende do controle exercido no laboratório.

\subsection{Conceito de empacotamento de partículas}

Nos últimos anos, o interesse pelo conceito de empacotamento de partículas aumentou nas diferentes áreas da engenharia, o que pode ser explicado pelo fato de que grande parte dos materiais naturais ou industriais utilizados diariamente são - ou contêm - partículas de diferentes formas e tamanhos [7].

A análise da distribuição do tamanho das partículas que compõem o material em estudo tem se mos- 
trado um procedimento eficiente no desenvolvimento e produção de materiais cerâmicos, principalmente na área de refratários, onde o objetivo é obter material com alta densidade. Na construção civil, o empacotamento se faz necessário na obtenção de concretos especiais, visto que a distribuição do tamanho de partículas afeta a densidade de empacotamento do agregado, sendo menor o volume de vazios a ser preenchido com a pasta de cimento quanto maior for a densidade de empacotamento [8, 9]. Portanto, a modificação da formulação de dosagem de concretos por meio da técnica de empacotamento de partículas é uma forma eficiente para auxiliar na produção de materiais com durabilidade e desempenho mecânico superiores com redução do consumo de cimento [10].

O estudo do empacotamento de partículas pode ser definido como o estudo da correta seleção da proporção e do tamanho adequado dos materiais particulados de uma composição, de forma que os vazios maiores sejam preenchidos por partículas menores, cujos vazios serão novamente preenchidos com partículas ainda menores e, assim, sucessivamente [11]. Tal conceito teve como propósito inicial determinar uma distribuição do tamanho de partículas que resultasse na maior densidade de empacotamento. Porém, com avanço nos estudos, verificou-se que essa ideia não garante a eficiência máxima de empacotamento, ou seja, parâmetros além do tamanho de partículas influenciam no resultado.

Dentre os vários fatores que afetam o empacotamento - morfologia, porosidade, densidade das partículas, efeito de parede, técnica de compactação - o estado de dispersão das partículas é o que influi diretamente na trabalhabilidade e demais propriedades do concreto no estado fresco [12-14]. Partículas finas tendem a ser submetidas a forças coesivas interparticulares (forças de Van der Waals) formando pequenos aglomerados de partículas [15]. Este é o caso das partículas de cimento, que apresentam uma grande tendência à aglomeração quando entram em contato com um líquido tão polar quanto a água. Assim, as partículas aglomeradas criam uma rede aberta de canais entre si, onde fica aprisionada parte da água que deveria ser usada para fluidificar a mistura. Desta forma, para se obter uma mistura fluida - ou seja, com a trabalhabilidade desejada - sem aumentar a relação água/cimento, torna-se necessária a utilização de aditivos químicos, plastificante e/ou superplastificante, que geram um efeito dispersante entre as partículas de cimento.

Em 1892, Féret publicou o primeiro tratado sobre o empacotamento de partículas em concreto. Desde então, modelos de empacotamento têm sido propostos como ferramenta para calcular a densidade de empacotamento das partículas e, assim, otimizar misturas granulares de concretos [16,17]. Os modelos de empacotamento de partículas esféricas são exemplos da teoria fractal e apresentam-se por meio de equações matemáticas que prescrevem como partículas de diferentes tamanhos irão interagir geometricamente. A densidade de empacotamento teórica de uma determinada mistura é calculada por esses modelos tendo como base a distribuição granulométrica. De uma forma geral, no caso de partículas esféricas, o empacotamento aleatório de monodispersões resulta sempre em um mesmo fator de empacotamento. Porém, a forma das partículas dos materiais granulares que comumente compõem as misturas de concreto está distante de uma esfera e deve-se admitir que, tradicionalmente na tecnologia dos concretos, pouca atenção é dada à busca por uma distribuição granulométrica ótima dessas partículas.

Estudos teóricos e experimentais do empacotamento de partículas geraram duas abordagens básicas deste problema: a abordagem discreta, que considera as partículas individualmente, utilizada pelo modelo de Furnas; e a abordagem contínua, que trata as partículas como distribuições contínuas, apreciada pelo modelo de Andreasen. Entre os modelos disponíveis na literatura, os estudiosos Funk e Dinger [18], após uma extensa análise comparativa, provaram que os modelos de Furnas e Andreasen convergiam matematicamente para uma mesma equação (Equação 1). Tal equação é conhecida como modelo de Alfred, a qual introduziu o conceito de tamanho mínimo de partícula, destacando-se na dosagem de concretos por possuir maior eficiência de empacotamento e ser mais condizente com sistemas particulados reais [19].

$$
\operatorname{CPFT}(\%)=\left(\frac{D^{q}-D_{S}^{q}}{D_{L}^{q}-D_{S}^{q}}\right) \times 100
$$

Onde: CPFT é a porcentagem acumulada de partículas menores que o diâmetro $\mathrm{D}$; $\mathrm{D}_{\mathrm{S}}$ é o diâmetro da menor partícula da distribuição; $\mathrm{D}_{\mathrm{L}}$ o diâmetro da maior partícula na distribuição; e q é uma constante, designada por coeficiente ou módulo de distribuição.

Por meio de simulações computacionais, verificou-se que para o modelo de Alfred a máxima densidade de empacotamento ocorre quando o valor do coeficiente de distribuição (q) assume valores iguais ou inferiores a 0,37 , enquanto que para valores acima é sempre verificada uma porosidade residual; já para coeficientes baixos $(\mathrm{q}<0,20)$ obtém-se um grande aumento na área superficial das partículas, reduzindo a fluidez [2, 
$11,14,18]$.

Com relação ao comportamento das misturas no estado fresco com alta densidade de empacotamento, isso é considerado um desafio, sendo sugeridos coeficiente de distribuição menores para atingir alta fluidez das misturas [2]. Para os concretos que apresentam boa capacidade de escoamento é recomendado que o valor do coeficiente de distribuição seja inferior a 0,30: valores próximos a 0,30 devem ser considerados para misturas adensadas sob vibração, enquanto valores entre 0,20 e 0,25 resultam em misturas autoadensáveis, em virtude da maior quantidade de finos; para valores maiores que 0,37 a mistura não alcança o empacotamento perfeito, por apresentar uma porosidade excedente [20]. O efeito da redução do valor do coeficiente de distribuição se dá no aumento da quantidade de finos, que influencia a interação entre as partículas.

\subsection{Justificativa}

No cenário brasileiro, para a dosagem de concreto, ainda são aplicados os métodos de dosagem tradicionais, que foram concebidos inicialmente para concretos convencionais. Entretanto, como desenvolvimento das obras de engenharia, elevou-se a necessidade de utilizar concretos especiais e, para tanto, esses métodos clássicos foram adaptados a fim de atender as novas exigências do mercado.

Em geral, as metodologias tradicionais de dosagem de concreto buscam a distribuição granulométrica ideal dos agregados individualmente. Entretanto, o concreto é constituído por diversos outros materiais granulares, não havendo a mesma orientação de continuidade para a mistura como um todo. Dessa forma, o comportamento do concreto depende parcialmente das propriedades individuais dos materiais que o compõem, mas no sentido amplo, as mesmas interações não são respeitadas. Nesse contexto, surge o conceito de empacotamento de partículas, amplamente aplicado em áreas da engenharia que exigem um maior grau de desenvolvimento tecnológico para produzir materiais com elevada performance. Tal estudo contempla o coeficiente de distribuição, parâmetro que mede de forma indireta a eficiência de empacotamento das composições. Na construção civil essa metodologia é aplicada particularmente para a produção de concretos de ultraalto desempenho, porém em concretos convencionais fica limitada, na maioria dos casos, à determinação simplificada do esqueleto granular considerando apenas os agregados constituintes da mistura.

Assim, esse trabalho tem como objetivo avaliar a eficiência do empacotamento de partículas de misturas de concretos de cimento Portland, convencionais e de alta resistência amplamente aplicados na construção civil, dosados por meio do método de dosagem tradicional IPT/EPUSP. Para isso, foi considerado o modelo de empacotamento de Alfred por ser um modelo matemático largamente utilizado em dosagens de concretos com alta eficiência de empacotamento, e também por ser mais adequado para sistemas reais por considerar os diâmetros máximo e mínimo das partículas, permitindo um melhor ajuste entre as curvas experimental e teórica para os concretos [2]. A determinação do coeficiente de distribuição permite uma discussão sobre os valores apresentados na literatura e motiva o estudo de otimização de dosagem desses concretos a partir do conceito de empacotamento de partículas, visto que essa metodologia pode ser aplicada ao concreto a fim de aprimorar suas propriedades de uma maneira sustentável, isto é, as propriedades do concreto no estado endurecido são melhoradas considerando misturas com menor consumo de cimento quando comparadas àquelas dosadas a partir dos métodos tradicionais.

\section{MATERIAIS E MÉTODOS}

O programa experimental empregado possui duas etapas principais com a finalidade de atingir o objetivo proposto. A primeira etapa consiste na determinação e validação dos traços de referência para as resistências mecânicas requeridas de dois concretos convencionais (C25-R e C40-R) e de um concreto de alta resistência (C80-R). Conhecendo a proporção e a distribuição granulométrica dos materiais constituintes desses concretos, o coeficiente de distribuição de cada mistura foi determinado considerando o modelo de empacotamento de Alfred. Na sequência, foram desenvolvidos traços otimizados, mantendo-se o mesmo coeficiente de distribuição. Para a dosagem das misturas de referência adotou-se o método tradicional IPT/EPUSP [6], bastante simples, eficiente e amplamente aplicado na prática da construção civil brasileira. Na segunda etapa, que contemplou a otimização das misturas, aplicou-se o conceito de empacotamento de partículas (modelo de Alfred).

\subsection{Materiais}

Os insumos empregados para a produção dos concretos foram cimento Portland composto com pozolana, de classe de resistência de $32 \mathrm{MPa}$ (CPII Z 32), com massa específica de 3,05 kg/dm³, pelo fato de ser um ci- 
mento de aplicações gerais em vários tipos de obras. No concreto de alta resistência também foi utilizada sílica ativa derivada do processo de produção de silício metálico, com massa específica de $2,21 \mathrm{~kg} / \mathrm{dm}^{3}$.

Os agregados miúdos utilizados foram duas areias naturais, de origem quartzosa, classificadas como areia fina e média, com massas específicas de $2,58 \mathrm{~kg} / \mathrm{dm}^{3}$ e $2,57 \mathrm{~kg} / \mathrm{dm}^{3}$, módulo de finura de 1,2 e 2,4 , e dimensão máxima característica de $0,6 \mathrm{~mm}$ e $2,36 \mathrm{~mm}$, respectivamente. Como agregados graúdos foram empregados três britas de origem basáltica, classificadas comercialmente como brita 1 , brita 0 e pedrisco, com massa específica de $2,96 \mathrm{~kg} / \mathrm{dm}^{3}, 2,99 \mathrm{~kg} / \mathrm{dm}^{3}$ e $2,84 \mathrm{~kg} / \mathrm{dm}^{3}$, e dimensão máxima característica de $19 \mathrm{~mm}$, $9,5 \mathrm{~mm}$ e $6,3 \mathrm{~mm}$, respectivamente.

Em todas as misturas produzidas foi utilizada água proveniente da rede de abastecimento local, de acordo com a NBR 15900-1:2009 [21]. Como as relações água/cimento de cada mistura foram mantidas constantes, para se alcançar a consistência desejada, foram empregados aditivos plastificante e superplastificante (à base de policarboxilatos) na produção dos concretos convencionais e de alta resistência, respectivamente.

\subsection{Dosagem dos concretos de referência}

Inicialmente foi realizado um estudo de dosagem aplicando-se o método IPT/EPUSP, para dois conjuntos de concretos, convencional e de alta resistência, fixando-se um teor ideal de argamassa de $53 \%$ e $63 \%$, e teor de água/materiais secos de $8,5 \%$ e $6,7 \%$, respectivamente, e um abatimento de $(120 \pm 20) \mathrm{mm}$ para ambos os conjuntos produzidos. O método de dosagem IPT/EPUSP prevê a composição entre agregados miúdos e/ou graúdos a fim viabilizar economicamente a mistura de concreto. No estudo, a composição ideal foi definida para o agregado miúdo (areias média e fina) com base no ensaio de massa unitária no estado compactado, realizado de acordo com a NBR NM 45:2006 [22], que apresentou um valor máximo quando a proporção de areia média/areia fina foi de 60/40 (Figura 1), sendo esta a proporção utilizada na produção dos concretos.

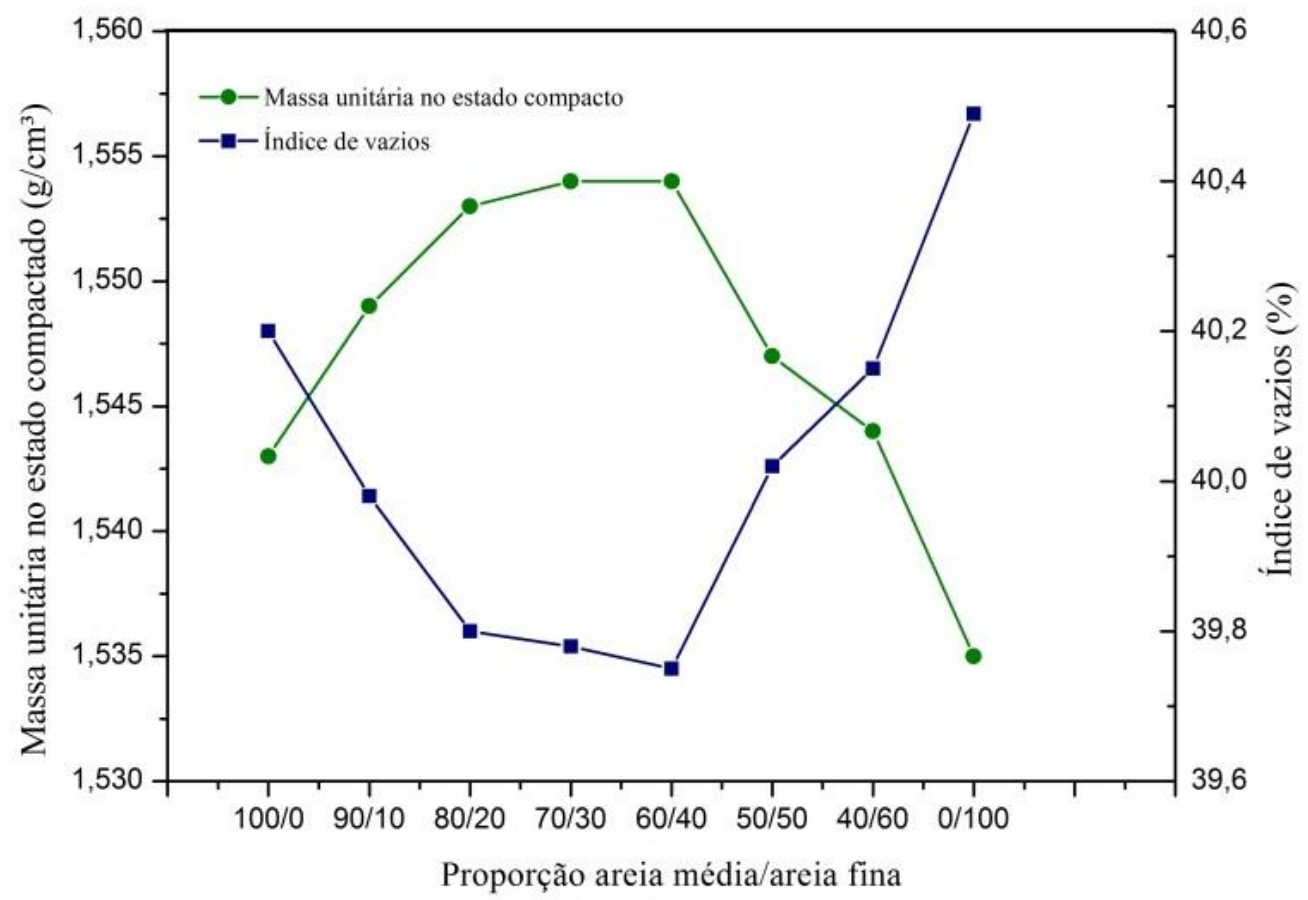

Figura 1: Massa unitária no estado compactado e índice de vazios em função da proporção de areia média/fina.

Definidos esses parâmetros iniciais produziu-se um diagrama de dosagem para cada conjunto de concreto (convencional e de alta resistência), e determinaram-se os traços de concreto de referência utilizados na pesquisa. Para o conjunto de concretos convencionais, empregaram-se dois traços com resistência característica à compressão $\left(\mathrm{f}_{\mathrm{ck}}\right)$ de $25 \mathrm{MPa}$ e $40 \mathrm{MPa}$; já para o concreto de alta resistência optou-se por um traço de resistência característica à compressão $\left(\mathrm{f}_{\mathrm{ck}}\right)$ de $80 \mathrm{MPa}$. Assim, para finalizar o planejamento experimental de dosagem, os traços pré-definidos com base no diagrama de dosagem obtido a partir do método IPT/EPUSP 
foram validados experimentalmente, originando os traços de referência C25-R, C40-R e C80-R.

\subsection{Análise dos coeficientes de empacotamento segundo o modelo de Alfred}

Todos os materiais granulares - cimento, sílica ativa, areia média, areia fina e brita - considerados na produção dos concretos de referência, foram caracterizados quanto à sua distribuição granulométrica, conforme apresentado na Figura 2. De posse dessa caracterização, a fim de verificar a eficiência do empacotamento das misturas de concreto, as composições obtidas a partir do método de dosagem tradicional foram avaliadas com base no modelo de Alfred. Nesta determinação, foram considerados diferentes fatores entre os descritores do tamanho das partículas $(2, \sqrt{2} e \sqrt[4]{2})$, a fim de verificar o que melhor retratasse aquele obtido por meio do método de dosagem tradicional IPT/EPUSP.

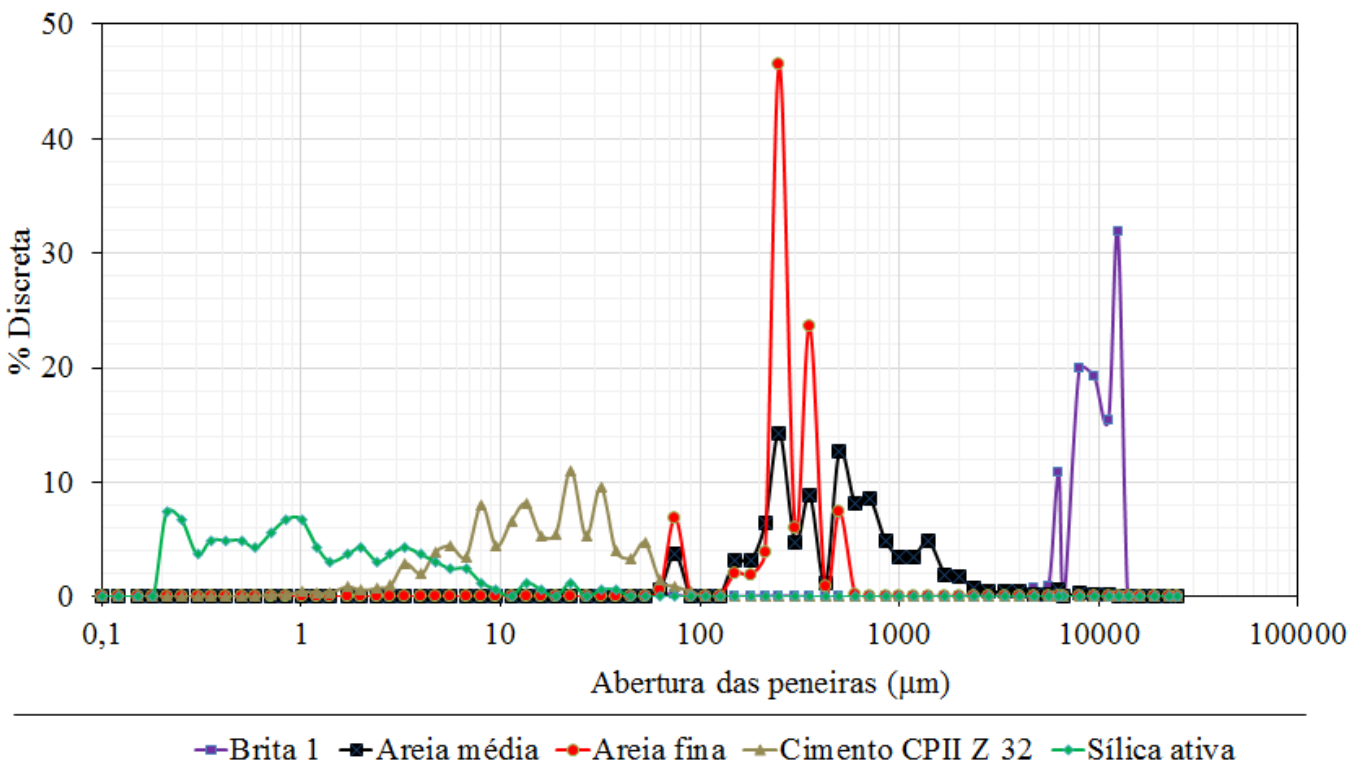

Figura 2: Distribuição discreta dos materiais constituintes dos concretos de referência.

Avaliando a distribuição granulométrica dos materiais e respeitando as diversas razões entre as sucessivas peneiras, verificou-se que dados mais detalhados são fornecidos quando considerados fatores entre os tamanhos das partículas menores, ou seja, uma distribuição granulométrica que reduz sucessivamente o intervalo entre as aberturas de peneiras proporciona uma melhor interpretação dos dados e torna possível a escolha dos materiais mais adequados para se obter a máxima eficiência de empacotamento, além de propiciar uma melhor representação da microestrutura do concreto. Por esse motivo, selecionou-se a razão $\sqrt[4]{2}$ para a distribuição dos materiais aplicados no estudo. Na prática da construção civil, o fator 2 é amplamente utilizado, enquanto que em outras áreas que utilizam o conceito de empacotamento de partículas, os fatores $\sqrt{2} e \sqrt[4]{2}$ são frequentemente aplicados.

Para cada mistura de concreto de cimento Portland produzida, definiu-se o coeficiente de distribuição de partículas, determinando-o de acordo com o modelo de empacotamento de Alfred. Para isso, as curvas de distribuição granulométrica discreta dos materiais granulares foram introduzidas no programa de cálculo (planilha Excel), desenvolvido para aplicação de misturas de concreto em geral, permitindo traçar uma curva experimental, considerando as proporções dos materiais obtidas a partir do estudo de dosagem com base no método tradicional IPT/EPSUSP. De forma simultânea, o programa delineia uma curva teórica em decorrência da implementação do modelo matemático de Alfred e, por meio de processo iterativo de otimização, determina-se o coeficiente de distribuição, de modo a maximizar o coeficiente de correlação $\left(\mathrm{R}^{2}\right)$ do ajuste entre a curva de distribuição experimental e a curva teórica proposta pelo modelo. Além disso, o programa fornece a comparação gráfica entre a curva experimental e a curva do modelo teórico utilizado.

Dessa forma, considerando as proporções e a distribuição granulométrica dos materiais granulares, definiu-se o coeficiente de distribuição para cada mistura de concreto de referência. A determinação do modelo de Alfred em detrimento aos outros modelos expostos na literatura foi principalmente pelo grande número de estudos que aplicaram esse modelo ao longo do tempo, especialmente na indústria cerâmica, pois tal método 
possibilita a obtenção de misturas com maior densidade de empacotamento e menor porosidade [2]. Além disso, o modelo de Alfred considera os limites para os tamanhos mínimo e máximo de partículas, possibilitando uma maior eficiência para os concretos considerados no estudo.

\subsection{Dosagem dos concretos de otimizados}

Os coeficientes de distribuição obtidos nos traços de referência foram mantidos para a otimização das misturas de concreto aplicando o conceito de empacotamento de partículas. Além disso, os concretos otimizados foram produzidos utilizando a mesma base de materiais granulares das misturas de referência, adicionando-se outros materiais granulares (o pedrisco e a brita 0), em função da ausência de partículas em determinadas faixas granulométricas das misturas de referência, conforme exposto nas Figuras 2 e 3. Dessa forma, a otimização de dosagem com base no conceito de empacotamento é realizada variando-se as possíveis combinações entre os materiais disponíveis a fim de preencher o máximo os vazios existentes.

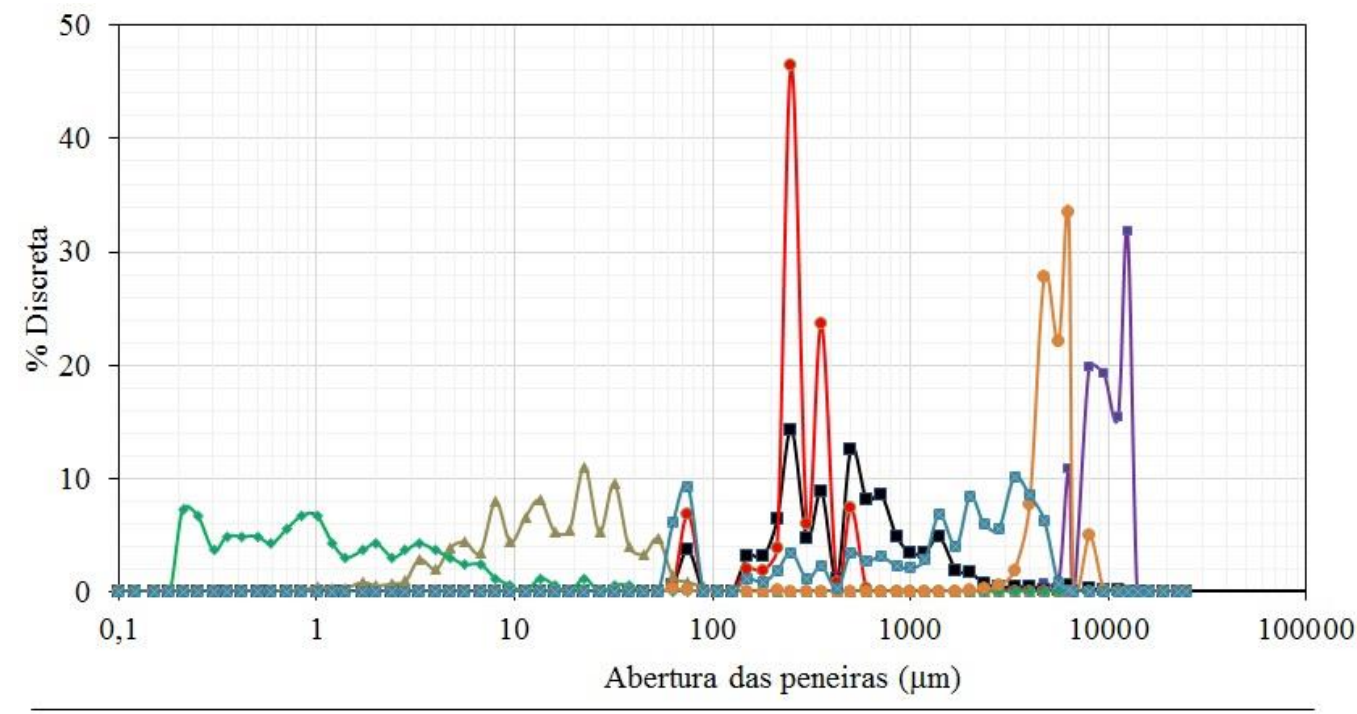

$\rightarrow$-Brita $1 \rightarrow$-Areia média $\rightarrow$-Areia fina $\rightarrow$ Cimento CPII Z $32 \rightarrow$-Sílica ativa $\rightarrow$-Brita $0 \rightarrow$-Pedrisco

Figura 3: Distribuição discreta dos materiais constituintes dos concretos de otimização.

É importante ressaltar que durante o processo de otimização das misturas de concreto não foi realizada a separação dos agregados em faixas granulométricas específicas, visto que essa manobra torna o processo de produção industrial inviável tanto do ponto de vista técnico quanto econômico, uma vez que os materiais não são comercializados separadamente por faixa granulométricas.

Ao realizar o processo inverso da obtenção do coeficiente de distribuição das misturas de referência, foi possível determinar as proporções em massa de cada componente da mistura otimizada. Logo, o arranjo entre os materiais (porcentagem de material em massa), que forneça o máximo coeficiente de correlação entre a curva de distribuição teórica (modelo de Alfred) e a curva de distribuição experimental idealizada para o traço de concreto, resulta nas misturas de concreto otimizadas identificadas como C25-OT, C40-OT, C80-R no presente trabalho. Cabe lembrar que o método de dosagem aplicado para otimização manteve constante o teor de água/materiais secos, possibilitando a determinação da relação água/cimento, visto que a técnica modifica completamente a composição da mistura.

\subsection{Etapa de mistura, moldagem e cura das amostras}

As misturas de concreto foram produzidas utilizando materiais secos, em betoneira de eixo inclinado com capacidade de 120 litros. O procedimento de mistura obedeceu a seguinte ordem: mistura-se inicialmente $75 \%$ da água de amassamento com os agregados graúdo e miúdo por 1 minuto; em seguida, acrescenta-se o cimento (e a sílica ativa, no caso do concreto de alta resistência) e o restante da água, e homogeneiza a mistura por 5 minutos; por fim, o aditivo plastificante ou superplastificante era então incorporado à mistura, que prosseguia por mais 5-7 minutos, garantindo a completa homogeneização do material. Como as relações água/cimento e água/aglomerante foram mantidas constantes, o teor de aditivo foi ajustado durante o proce- 
dimento de mistura do concreto, até que a mistura apresentasse o abatimento dentro do intervalo proposto.

Corpos de prova foram moldados, adensados mecanicamente com o auxílio de uma mesa vibratória, sendo protegidos no topo para evitar a perda de umidade do concreto para o meio ambiente. Depois de 24 horas os corpos de prova foram desmoldados e submetidos a um regime de cura úmida até as idades de interesse (7, 28 e 91 dias). Para cada traço de concreto produzido foram moldados 21 corpos de prova cilíndricos, com dimensões de $100 \mathrm{~mm}$ de diâmetro e $200 \mathrm{~mm}$ de altura. A quantidade de corpos de prova foi determinada para a execução de ensaios físicos e mecânicos no estado endurecido, visando atender uma quantidade de amostras que permitisse o desenvolvimento de uma análise estatística, a fim de obter um maior nível de confiabilidade da amostra.

\subsection{Avaliação das propriedades dos concretos}

A avaliação das propriedades físicas dos concretos foi realizada a partir da determinação da massa específica, absorção de água por imersão e índice de vazios de cada concreto no estado endurecido, nas idades de 28 e 91 dias, conforme a NBR 9778:2005 [23], considerando-se 3 corpos de prova para cada classe de resistência e idade de interesse. Quanto às propriedades mecânicas, foi determinada a resistência à compressão dos concretos nas idades de 7, 28 e 91 dias, conforme a NBR 5739: 2007 [24], tendo sido moldados 5 corpos de prova para cada classe de resistência e idade analisada.

\section{RESULTADOS E DISCUSSÕES}

\subsection{Determinação do coeficiente de distribuição}

A dosagem de concretos pelas metodologias clássicas visa componentes com granulometria contínua individualmente, com foco principal nos agregados miúdo e graúdo. Porém, o concreto é composto por outros materiais granulares como o cimento e as adições minerais, cuja distribuição granulométrica não é considerada no estudo de dosagem utilizando os métodos tradicionais. Assim, uma forma de tratar a continuidade em termos de distribuição granulométrica na mistura se dá por meio de modelos de empacotamento de partículas, os quais consideram os efeitos geométricos e de interação entre os grãos de todos os materiais granulares que compõem uma mistura de concreto.

Diante do exposto, na primeira etapa da avaliação da eficiência do empacotamento de partículas das misturas obtidas a partir de métodos de dosagem tradicional realizou-se uma análise conjunta da distribuição granulométrica dos materiais constituintes considerados no estudo, conforme observado na Figura 2. Verifica-se a ausência de determinadas faixas granulométricas e sobreposição de alguns materiais como as areias fina e média, caracterizando uma deficiência dessas composições em termos de empacotamento.

Com a finalidade de realizar uma avaliação mais precisa da eficiência de empacotamento das misturas dosadas a partir de métodos tradicionais, conhecendo-se a distribuição granulométrica e as proporções dos materiais granulares constituintes dos concretos, o modelo de empacotamento de Alfred foi aplicado. Assim, foi obtida a curva de distribuição granulométrica real de cada mistura de concreto e, então, aplicando-se o modelo de Alfred (curva teórica), foi possível determinar o coeficiente de distribuição de cada mistura, conforme exposto na Figura 4.

(a)

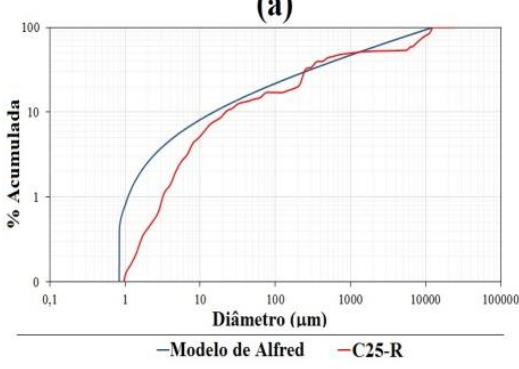

(b)

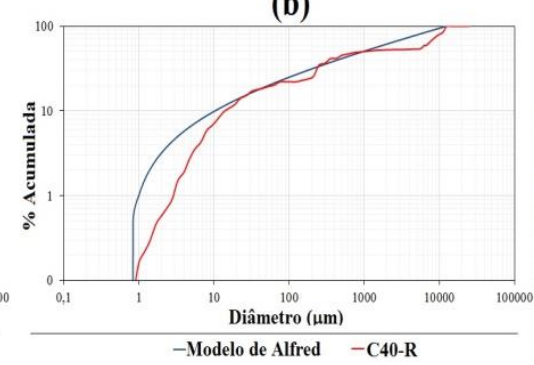

(c)

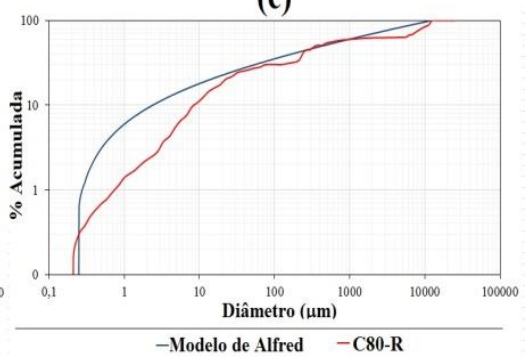

Figura 4: (a) Curva de distribuição granulométrica do C25-R; (b) Curva de distribuição granulométrica do C40-R; (c) Curva de distribuição granulométrica do C80-R. 
A curva teórica de distribuição do modelo de Alfred foi ajustada, por meio de otimização computacional, de forma a se aproximar o máximo possível da curva de distribuição da composição de concreto (curva real), ou seja, obter o máximo valor do coeficiente de correlação $\left(\mathrm{R}^{2}\right)$ entre as curvas teórica e experimental. Os valores do coeficiente de distribuição (q) e do coeficiente de correlação obtidos para cada mistura de concreto de referência foram $0,27\left(R^{2}=0,962\right), 0,23\left(R^{2}=0,959\right)$ e $0,16\left(R^{2}=0,971\right)$ para os concretos $C 25-R$, C40-R e C80-R, respectivamente. A partir dos gráficos apresentados na Figura 4, observa-se que os coeficientes de correlação não atingiram seu valor máximo $\left(\mathrm{R}^{2}=1,0\right)$ devido, principalmente, à deficiência de materiais com granulometria mais fina, no intervalo de 0,1 a $10 \mu \mathrm{m}$, parte em que a curva teórica está mais afastada da curva de distribuição experimental.

Em termos de consistência, os concretos convencionais e de alta resistência foram adensados por vibração mecânica, obtendo valores de abatimento dentro da faixa estabelecida (120 $\pm 20 \mathrm{~mm})$. Dessa forma, dado o tipo de adensamento previsto para esses concretos, eram esperados valores de coeficiente de distribuição próximos a $0,30[11 ; 20,25]$. Entretanto, com relação à densidade de empacotamento, os valores de coeficiente de distribuição obtidos se aproximam daqueles estabelecidos para misturas autoadensáveis (normalmente entre 0,20 e 0,25$)$. $\mathrm{O}$ valor do coeficiente de distribuição $(\mathrm{q}=0,16)$ definido para o concreto de alta resistência é relativamente baixo em comparação com o proposto por Oliveira et al. [19], que apresentou um coeficiente de distribuição de 0,29, atingindo valores de resistência média à compressão de (64 \pm 3$) \mathrm{MPa}$.

O modelo de empacotamento adotado considera na sua formulação que as partículas são perfeitamente esféricas, desconsiderando a influência da morfologia das mesmas, consistindo em uma limitação do modelo teórico aplicado para obter distribuições de partículas reais que se afastam de uma esfera. De uma forma geral, no caso de partículas esféricas, o empacotamento aleatório de monodispersões resulta sempre em um mesmo fator de empacotamento. Porém, a forma das partículas dos materiais granulares que comumente compõem as misturas de concreto está distante de uma esfera e deve-se admitir que, tradicionalmente na tecnologia dos concretos, pouca atenção é dada à busca por uma distribuição granulométrica ótima dessas partículas. Além disso, ao estudar o comportamento dos concretos depara-se com um problema relacionado com a garantia de se reproduzir materiais com uma distribuição granulométrica precisa, isto é, as matérias-primas nem sempre apresentam uma distribuição granulométrica contínua e reprodutível ao longo do tempo [7].

\subsection{Otimização da dosagem dos concretos}

$\mathrm{Na}$ otimização da dosagem das misturas de concreto de referência com base no conceito de empacotamento de partículas aplicou-se uma análise conjunta da granulometria discreta dos materiais constituintes, sendo incorporados novos componentes granulares nesta etapa. Na Figura 2 verifica-se que as misturas de concreto de referência apresentam uma ausência de partículas com dimensões entre algumas faixas granulométricas, isto é, entre a areia média e a brita 1, e entre o cimento e areia fina, além de uma sobreposição granulométrica de frações de areia fina e areia média, problemática verificada também por Oliveira et al. [19]. Logo, uma nova composição foi elaborada com a finalidade de aumentar a densidade de empacotamento de partículas, conforme visto na Figura 3. Uma mistura que dispõe de um maior número de componentes pode apresentar um melhor preenchimento dos vazios, uma vez que há mais variedade de tamanho de grãos [26].

As novas proporções dos materiais particulados foram determinadas por meio de um processo de otimização matemática, que utilizava como dados de entrada a distribuição granulométrica discreta dos componentes da mistura e o coeficiente de distribuição determinado anteriormente nos concretos de referência. A Figura 5 apresenta a distribuição granulométrica dos concretos otimizados com base no conceito de empacotamento de partículas, mantendo-se os coeficientes de distribuição determinados anteriormente para cada mistura de concreto de referência.

(a)

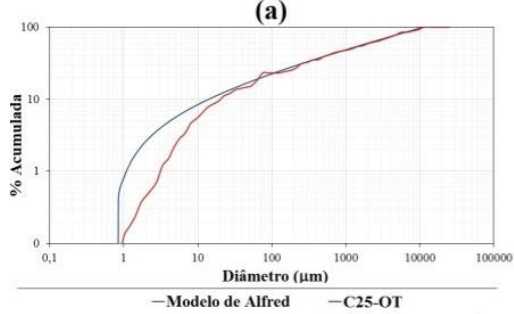

(b)

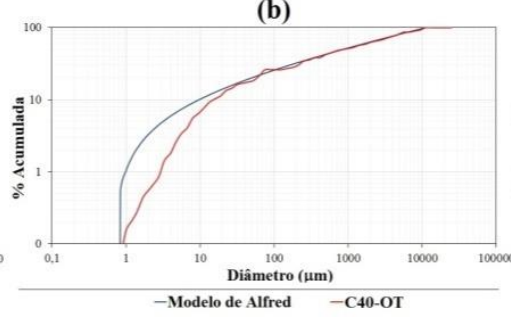

(c)

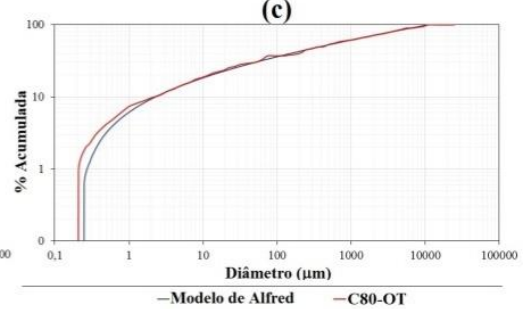

Figura 5: Curvas de distribuição granulométricas otimizadas para os concretos: (a) C25-OT; (b) C40-OT, (c) C80-OT. 
A partir dos gráficos apresentados na Figura 5 observa-se uma pequena dispersão entre as curvas teórica e experimental, já que os modelos de empacotamento de partículas são elaborados a partir de simplificações e de dados experimentais de um determinado conjunto de materiais. Tais modelos não levam em consideração a forma das partículas e considera que cada partícula é posicionada uma a uma na mistura [27].

Além disso, de acordo com os gráficos da Figura 5, é verificada uma boa homogeneidade da otimização de dosagem, com elevados valores para os coeficientes de correlação entre as curvas experimental e teórica do modelo, sendo obtidos valores de $\mathrm{R}^{2}$ iguais a 0,9984, 0,9981 e 0,9991 para os concretos C25-OT, C40-OT e C80-OT, respectivamente. Vale ressaltar que os concretos convencionais (C25-OT e C40-OT) possuem uma dispersão de resultados no intervalo de 1 a $10 \mu \mathrm{m}$ em virtude da falta de materiais comerciais nessa fração uma vez que não foi considerado o uso de sílica ativa na produção desses concretos, fazendo com que a curva experimental se afastasse da curva teórica (modelo de Alfred).

\subsection{Definição dos traços de concreto}

Elaborados os diagramas de dosagem para as duas famílias de concreto (concretos convencionais e de alta resistência), definiram-se os traços de referência de cada classe de resistência, e posteriormente, realizou-se a validação experimental dessas misturas de concreto com resistência característica à compressão de 25,40 e $80 \mathrm{MPa}$, aos 28 dias de idade. Na sequência, foram desenvolvidos traços de concreto otimizados com base no conceito de empacotamento de partículas (modelo de Alfred), mantendo-se o mesmo coeficiente de distribuição. A composição dos concretos produzidos (referência e otimizados) e os valores de abatimento medidos são apresentados na Tabela 1 .

Tabela 1: Consumo de materiais $\left(\mathrm{kg} / \mathrm{m}^{3}\right.$ de concreto) e valor de abatimento dos concretos utilizados na pesquisa.

\begin{tabular}{ccccccc}
\hline Identificação & C25-R & C25-OT & C40-R & C40-OT & C80-R & C80-OT \\
\hline Cimento & 332,16 & 364,74 & 453,77 & 439,75 & 607,35 & 420,82 \\
\hline Sílica ativa & - & - & - & - & 50,16 & 302,99 \\
\hline Pedrisco & - & 959,28 & - & 914,67 & & 799,55 \\
\hline Brita 0 & - & 178,72 & - & 162,71 & & 92,58 \\
\hline Brita 1 & 1062,91 & 386,63 & 1066,35 & 351,80 & 877,29 & 269,32 \\
\hline Areia fina & 345,45 & - & 299,49 & - & 326,62 & 29,46 \\
\hline Areia Média & 518,17 & 412,16 & 449,23 & 444,14 & 489,93 & 429,23 \\
\hline Água & 192,65 & 196,96 & 195,12 & 197,89 & 157,91 & 155,70 \\
\hline Aditivo Plastificante & 0,80 & 4,38 & 1,23 & 5,28 & - & - \\
\hline Aditivo Superplastificante & - & - & - & - & 4,98 & 9,80 \\
\hline Abatimento (mm) & 128 & 25 & 123 & 20 & 117 & 213 \\
\hline
\end{tabular}

Os concretos com esqueleto granular modificado (C25-OT, C40-OT e C80-OT), que passaram pelo processo de otimização aplicando o conceito de empacotamento de partículas, demandaram maiores quantidades de agregados em relação aos concretos de referência, tendência também verificada em outros estudos sobre o assunto [2, 26, 28]. Ainda com relação ao consumo de materiais, verificou-se que a inserção de novos materiais (brita 0 e pedrisco) associados com a areia média proporcionou um melhor empacotamento da mistura. A redução drástica da proporção de areia fina é justificada por dois motivos principais: (i) esta apresentava alta proporção de partículas com diâmetro entre 100 a $1000 \mu \mathrm{m}$ e (ii) a distribuição granulométrica da areia média combinada ao pedrisco tornou dispensável a fração de areia fina na composição final.

O emprego do conceito de empacotamento de partículas permite formular novas composição de concretos, em geral, com menor consumo de cimento por metro cúbico de concreto. Entretanto, no traço de concreto de alta resistência otimizado (C80-OT) é possível observar um aumento do consumo de sílica ativa devido ao ajuste da fração mais fina da curva de distribuição, realizada em grande parte pelas partículas dessa adição mineral. Dessa forma, o consumo de materiais isoladamente não é um parâmetro suficiente para verificar a sustentabilidade ambiental dos concretos tendo em vista que a otimização dos traços com base no con- 
ceito de empacotamento modificou diversos parâmetros de dosagem fixados inicialmente, inviabilizando a comparação entre as amostras.

No estado fresco verificou-se perda sistemática da trabalhabilidade das misturas otimizadas em relação às misturas de referência, sendo necessário o aumento do consumo de aditivo a fim de dispersar as partículas da mistura e atingir a consistência suficiente para moldagem das amostras. A elevação da concentração de sólidos amplia o contato entre as partículas. Nestas condições são necessárias maiores tensões para manter o fluxo do concreto, com um aumento na viscosidade, não permitindo a dispersão do material apenas com uso de aditivo plastificante e/ou superplastificante [29]. Conforme constatado nem sempre é possível atingir uma determinada consistência adicionando apenas aditivo químico. Para concretos otimizados com base no conceito de empacotamento de partículas, algumas vezes é necessário alterar o teor de argamassa do concreto, ou ainda aumentar o teor de água/matérias secos a fim de conferir maior mobilidade à mistura, desde que não tenha efeito negativo sobre a resistência mecânica do material.

\subsection{Avaliação das propriedades físicas dos concretos}

A durabilidade em misturas de concreto está intimamente relacionada ao processo em que a água penetra, difunde ou percola agentes agressivos do meio ambiente através da estrutura de poros do material, sendo considerada como o fator primordial para a maioria dos problemas de deterioração das estruturas de concreto [1,30]. A grande maioria das especificações que permite prever a durabilidade das misturas de concreto está atrelada às propriedades físicas do material, sendo esta linha de raciocínio tradicional e bem difundida mundialmente. Helene [31], Mehta e Monteiro [1] são enfáticos ao afirmar que a durabilidade do concreto está relacionada com a permeabilidade, ou seja, depende da conectividade entre os poros presentes no material.

Helene [31] estabelece que para um concreto ser durável a absorção de água deve ser no máximo $4,2 \%$, enquanto uma absorção máxima de $6,3 \%$ é especificada para um concreto normal em termos de durabilidade; acima de 6,3\% o concreto é considerado deficiente. No caso de índice de vazios, os limites estabelecidos para um concreto ser considerado durável ou normal são, respectivamente, $10 \%$ e $15 \%$, sendo que acima de 15\%, o concreto é considerado deficiente. A International Tunnelling Association [32] classifica como tolerável a qualidade dos concretos com absorção de água entre $8 \%$ e $9 \%$, e ruim acima de $9 \%$. Para índice de vazios, a mesma referência considera de qualidade razoável os concretos com índice de vazios entre $17 \%$ e $19 \%$, e ruim quando superior a $19 \%$. As propriedades físicas para cada tipo de concreto produzido estão dispostas na Tabela 2.

Tabela 2: Valores de absorção de água por imersão e índice de vazios dos concretos produzidos.

\begin{tabular}{c|c|c|c|c|c}
\hline Tipo de concreto & Idade (dias) & Absorção (\%) & DP $(\%)$ & Índice de vazios (\%) & DP $(\%)$ \\
\hline \multirow{3}{*}{ C25-R } & 28 & 4,42 & 0,22 & 10,22 & 0,35 \\
\cline { 2 - 6 } & 91 & 3,58 & 0,17 & 8,49 & 0,39 \\
\hline \multirow{3}{*}{ C25-OT } & 28 & 3,99 & 0,06 & 9,56 & 0,11 \\
\cline { 2 - 6 } & 91 & 3,38 & 0,30 & 8,16 & 0,63 \\
\hline \multirow{3}{*}{ C40-R } & 28 & 3,62 & 0,25 & 8,49 & 0,58 \\
\hline \multirow{3}{*}{ C40-OT } & 91 & 2,04 & 0,07 & 4,87 & 0,18 \\
\cline { 2 - 6 } & 91 & 3,68 & 0,11 & 8,81 & 0,27 \\
\hline \multirow{2}{*}{ C80-R } & 28 & 1,39 & 0,05 & 7,24 & 0,60 \\
\cline { 2 - 6 } & 91 & 1,19 & 0,04 & 3,42 & 0,10 \\
\hline \multirow{2}{*}{ C80-OT } & 28 & 1,33 & 0,05 & 2,96 & 0,10 \\
\cline { 2 - 6 } & 91 & 1,13 & 0,04 & 3,21 & 0,12 \\
\hline
\end{tabular}

Com relação aos ensaios balizadores de durabilidade, os resultados de absorção de água por imersão e índices de vazios apresentaram boa homogeneidade de resultados indicando que os concretos podem ser con- 
siderados duráveis com base nos limites especificados [26, 27, 31-33]. Uma ressalva apenas para o concreto C25 que é classificado como normal, aos 28 dias de idade, pois ficou um pouco acima do intervalo de excelência, mas adequando-se aos critérios para um concreto durável aos 91 dias de idade. Assim, todos os concretos produzidos apresentam um bom desempenho com relação ao critério de durabilidade, podendo ser utilizados nas obras correntes de construção civil. Tais resultados, referentes aos tipos de concreto, apresentam decréscimo com o prolongamento da idade e com a densificação da matriz cimentícia do concreto em decorrência das reações de hidratação do cimento ao longo do tempo. O sistema de poros com maior tortuosidade, resultante de um esqueleto granular mais bem empacotado e de microestrutura hidratada refinada, possibilitam mecanismos alternativos que favorecem a durabilidade [29].

\subsection{Avaliação das propriedades mecânicas dos concretos}

A evolução da resistência à compressão ao longo do tempo de cada mistura de concreto produzida é apresentada na Figura 6. Os valores correspondem à média de cinco resultados individuais obtidos em cada ensaio, conforme exposto na Tabela 3. Em relação aos valores individuais, observa-se uma baixa dispersão dos resultados, o que mostra uma boa homogeneidade da amostra. Em relação ao crescimento da resistência à compressão dos 28 aos 91 dias de idade, observou-se um percentual de ganho de resistência de 128,58\%, $116,82 \%$ e $116,53 \%$, respectivamente, para os concretos C25-R, C40-R e C80-R. Tal evolução da resistência mecânica do concreto depende, expressivamente, do tipo do cimento utilizado que, para o CP II Z 32 adotado no estudo, o percentual de resistência à compressão esperado aos 7 e 91 dias era de cerca de $80 \%$ e $112 \%$, respectivamente, da resistência aos 28 dias [30]. Ao analisar o percentual de resistência de cada conjunto, vêse uma discordância nesse critério, principalmente, em relação ao percentual de resistência à compressão da mistura de concreto C80-R, aos 7 dias, que aferiu 97,15\% da sua resistência de referência (para os 28 dias).

Tabela 3: Valores da resistência à compressão dos concretos produzidos ao longo do tempo.

\begin{tabular}{c|c|c|c|c|c|c|c|c|c|c|c|c}
\hline \multirow{2}{*}{$\begin{array}{c}\text { Idade } \\
(\text { dias })\end{array}$} & \multicolumn{2}{|c|}{$\mathrm{C} 25-\mathrm{R}$} & \multicolumn{2}{c|}{$\mathrm{C} 25-\mathrm{OT}$} & \multicolumn{2}{c|}{$\mathrm{C} 40-\mathrm{R}$} & \multicolumn{2}{c|}{$\mathrm{C} 40-\mathrm{OT}$} & \multicolumn{2}{c|}{$\mathrm{C} 80-\mathrm{R}$} & \multicolumn{2}{c}{$\mathrm{C} 80-\mathrm{OT}$} \\
\cline { 2 - 25 } & $\begin{array}{c}\mathrm{Rc} \\
(\mathrm{MPa})\end{array}$ & $\begin{array}{c}\mathrm{Rc} \\
(\mathrm{MPa})\end{array}$ & $\begin{array}{c}\mathrm{DP} \\
(\mathrm{MPa})\end{array}$ & $\begin{array}{c}\mathrm{Rc} \\
(\mathrm{MPa})\end{array}$ & $\begin{array}{c}\mathrm{DP} \\
(\mathrm{MPa})\end{array}$ & $\begin{array}{c}\mathrm{Rc} \\
(\mathrm{MPa})\end{array}$ & $\begin{array}{c}\mathrm{DP} \\
(\mathrm{MPa})\end{array}$ & $\begin{array}{c}\mathrm{Rc} \\
(\mathrm{MPa})\end{array}$ & $\begin{array}{c}\mathrm{DP} \\
(\mathrm{MPa})\end{array}$ & $\begin{array}{c}\mathrm{Rc} \\
(\mathrm{MPa})\end{array}$ & $\begin{array}{c}\mathrm{DP} \\
(\mathrm{MPa})\end{array}$ \\
\hline 7 & 22,78 & 2,21 & 30,77 & 3,12 & 31,94 & 2,32 & 35,88 & 2,25 & 60,59 & 3,35 & 56,99 & 1,92 \\
\hline 28 & 27,75 & 1,94 & 39,95 & 1,34 & 40,23 & 1,66 & 43,14 & 3,17 & 62,37 & 1,62 & 83,25 & 3,99 \\
\hline 91 & 35,68 & 1,85 & 44,39 & 6,13 & 47,00 & 0,22 & 61,24 & 3,08 & 72,68 & 7,58 & 113,34 & 2,89 \\
\hline
\end{tabular}

Nota: os valores da resistência à compressão correspondem à média de 5 determinações; $\mathrm{Rc}=$ Resistência à compressão; $\mathrm{DP}=$ Desvio-padrão $(\mathrm{MPa})$.

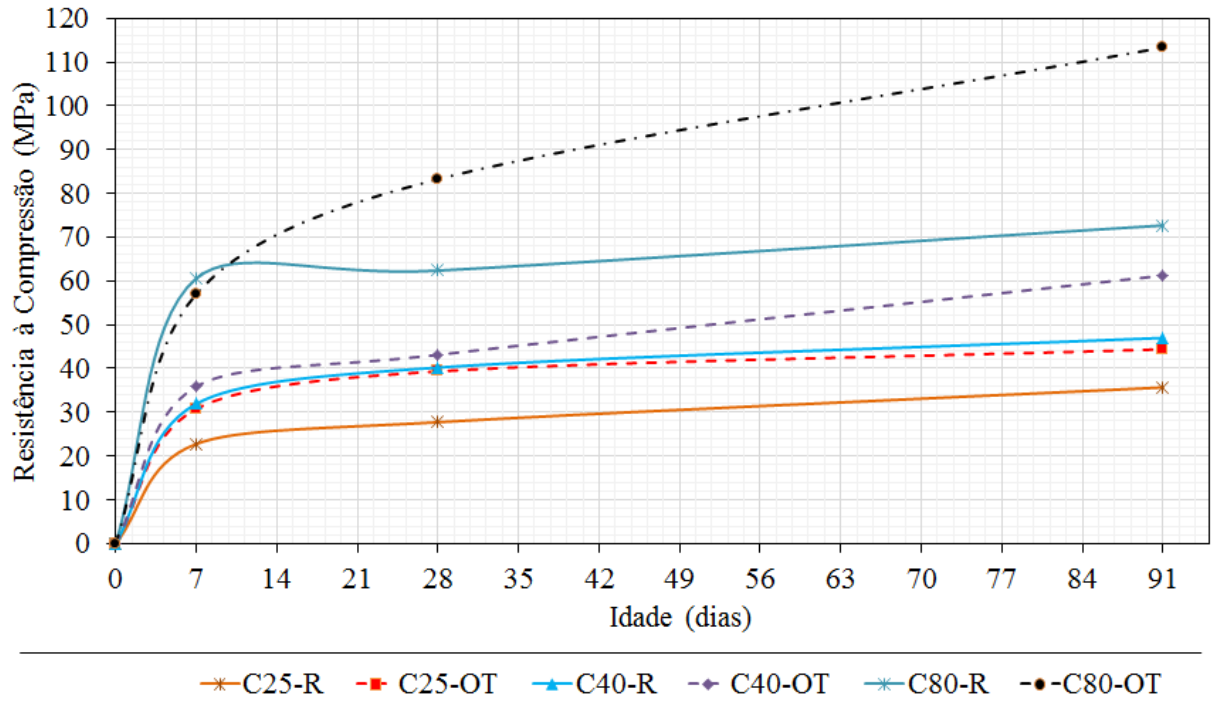

Figura 6: Evolução da resistência à compressão dos concretos produzidos ao longo do tempo. 
A aplicação do conceito de empacotamento de partículas na otimização dos concretos resultou no aumento de resistência mecânica em todas idades avaliadas, com exceção do C80-OT aos 7 dias. Nas primeiras idades, é evidenciado um acréscimo de resistência menor em relação às idades posteriores. Isso é atribuído à menor quantidade de agregado graúdo utilizada nessa composição, quando comparada à mistura de referência. Esse material favorece o desempenho mecânico nas primeiras idades, enquanto nas idades mais avançadas há contribuição do empacotamento de partículas dos materiais granulares e da matriz da pasta de cimento hidratada.

O concreto de alta resistência otimizado (C80-OT) apresenta desenvolvimento crescente da resistência à compressão além dos 28 dias de idade, enquanto a taxa de desenvolvimento de resistência para os outros concretos é reduzida após essa idade. Este comportamento é explicado pelo alto teor de adições minerais, responsáveis pelo fortalecimento da zona de transição na interface pasta/agregado, contribuindo com o aumento da resistência à compressão nas idades posteriores. Ainda com relação a otimização de dosagem do concreto de alta resistência é verificada uma variação significativa no valor da resistência média à compressão, aos 28 e 91 dias de idade, em relação ao concreto de referência (C80-R), com nível de confiança de $95 \%$. Detalhes da análise estatística estão disponíveis em Lopes [34].

A maior variação de resistência média à compressão para os concretos convencionais foi registrada no concreto C25-OT aos 28 dias, que apresentou um valor de resistência 41,83\% superior ao C25-R, enquanto que a menor alteração ocorreu no concreto C40-OT aos 28 dias, cuja resistência foi apenas 7,23\% superior em relação ao C40-R. De acordo com o teste t de Student realizado [34], observa-se que existe diferença significativa entre a resistência média à compressão dos concretos convencionais de classe $\mathrm{C} 25$ e C40, evidenciando a influência do empacotamento de partículas sobre o comportamento mecânico dos concretos.

\section{CONCLUSÕES}

Os métodos de dosagem clássicos implementados no país definem uma metodologia que busca misturas econômicas e que atenda aos critérios especificados em projeto. Entretanto, a técnica de dosagem dos concretos é bastante conservadora, não havendo grandes modificações ao longo do tempo. Deve-se salientar que a tecnologia atual de concretos não está errada, mas sim incompleta.

De maneira geral, o presente trabalho apresentou resultados satisfatórios da aplicação do conceito de empacotamento de partículas na avaliação da eficiência de misturas de concreto de cimento Portland. A partir da distribuição granulométrica dos materiais constituintes das misturas de referência, verificou-se a ausência de determinadas faixas granulométricas, o que compromete a máxima eficiência de dosagem quando utilizados métodos tradicionais de dosagem. Quando da otimização da dosagem do concreto com base no conceito de empacotamento de partículas, a fim de se obter uma distribuição contínua para a mistura, foi necessário considerar novos materiais constituintes granulares para suprimir as deficiências granulométricas verificadas nas misturas de referência, enquanto outros materiais constituintes inicialmente considerados foram descartados devido à sobreposição de faixas granulométricas, alterando a composição das misturas.

Considerando o modelo de empacotamento de Alfred e a curva de distribuição granulométrica experimental de cada mistura de concreto de referência, o coeficiente de distribuição foi determinado, sendo obtidos valores diferentes daqueles estabelecidos na literatura para concretos adensados por vibração. O modelo de empacotamento adotado (modelo de Alfred) considera na sua formulação partículas perfeitamente esféricas desconsiderando a influência da morfologia das mesmas. Sendo assim, esta é uma das limitações do modelo teórico aplicado para obter distribuições de partículas reais, o que resulta em uma dispersão entre os resultados.

Com relação a otimização da dosagem é observado um ganho significativo nas propriedades associadas à durabilidade e ao desempenho mecânico dos concretos quando o conceito de empacotamento de partículas foi aplicado para a obtenção da composição ideal de materiais. Porém, no estado fresco, o incremento de partículas decorrente do empacotamento implicou na redução da trabalhabilidade das misturas otimizadas, necessitando aumentar consideravelmente o consumo de aditivo para atingir a consistência desejada.

Assim, a implementação de modelos de empacotamento, com uma correta seleção de materiais, pode permitir um aumento do rendimento dos traços dosados, além do acréscimo de resistência mecânica para um consumo de cimento menor, aumentando a eficiência do uso de ligantes nas misturas e, com isso, tornando o concreto um material sustentável. 


\section{AGRADECIMENTOS}

Os autores gostariam de agradecer ao Conselho Nacional de Desenvolvimento Científico e Tecnológico (CNPq) pela bolsa de mestrado financiada, ao Laboratório de Estruturas da Escola de Engenharia de São Carlos (EESC/USP) pelo suporte oferecido na realização deste trabalho, e às empresas Grace Construction Products e Elkem Silicon Materials pela doação dos materiais utilizados na pesquisa.

\section{BIBLIOGRAFIA.}

[1] MEHTA, K., MONTEIRO P. J. M., Concreto. Microestrutura, Propriedades e Materiais, $4^{a}$ ed., São Paulo, Ibracon, 2014.

[2] GRAZIA, M. T., SANCHEZ, L. F. M., ROMANO, R. C. O., et al.,"Investigation of the use of continuous particle packing models (PPMs) on the fresh and hardened properties of low-cement concrete (LCC) systems", Construction and Building Materials, v. 195, pp. 524-536, 2018.

[3] HELENE, P., TUTIKIAN, B. "Dosagem dos Concretos de Cimento Portland". In: ISAIA, G.C. Concreto: Ciência e Tecnologia, São Paulo, Ipsis, v.1, pp. 415-452, 2011.

[4] RICCI, B. O. L., PEREIRA, A. M., AKASAKI, J. L., "Estudo de dosagens visando obter concretos para obras de pequeno porte", Fórum Ambiental da Alta Paulista, v. 13, pp. 182-194, 2017.

[5] ALENCAR, R. S. A., Dosagem do concreto autoadensável: produção de pré-fabricados. Dissertação de M.Sc, Universidade de São Paulo, São Paulo, 2008.

[6] HELENE, P. R. L., TERZIAN, P. Manual de dosagem e controle do concreto. São Paulo: PINI, Brasília, SENAI, 1992.

[7] CASTRO, A., FERREIRA, F., "Effect of particle packing in the durability of high performance concretes", Ingeniería de Construcción, v. 31, n. 2, pp. 91-104, 2016.

[8] KWAN, A. K. H., NG, P. L., HUEN, K. Y. "Effects of fines content on packing density of fine aggregate in concrete", Construction and Building Materials, n. 61, pp.270-277, 2014.

[9] NOEL, M., SANCHEZ, L., FATHIFAZL, G. "Recent advances in sustainable concrete for structural application", Sustainable Construction Materials \& Technologies, v. 4, pp. 1-10, 2016.

[10] DAMINELI, B. L., PILEGGI, R. G., JOHN, V. M. "Influence of packing and dispersion of particles on the cement content of concretes", Revista Ibracon de Estruturas e Materiais, v. 10, n. 5, pp. 998-1024, 2017.

[11] OLIVEIRA, I. R., STUDART, A.R., PILEGGI. Dispersão e Empacotamento de Partículas: Princípios e Aplicações em Processamento Cerâmico, São Paulo, Fazendo Arte Editorial, 2000.

[12] KNOP, Y., PELED, A. "Packing density modeling of blended cement with limestone having different particle sizes", Construction and Building Materials, v. 102, pp. 44-50, 2016.

[13] KNOP, Y., PELED, A. "Setting behavior of blended cement with limestone: influence of particle size and content", Materials and Structures, v. 49, n. 1-2, pp. 439-452, 2016.

[14] VARHEN, C., DILONARDO, I., ROMANO, C., et al., "Effect of the substitution of cement by limestone filler on the rheological behavior and shrinkage of microconcretes", Construction and Building Materials, v. 125, pp. 375-386, 2016.

[15] HERMANN, A., LANGARO, E. A., LOPES DA SILVA, S. H., et al., "Empacotamento de partículas de cimento e sílica ativa em pastas pelo uso de modelo analítico", Revista Ibracon de Estruturas e Materiais, v. 9, n. 1, pp. 48-65, 2016.

[16] LARRARD, F., SEDRAN, T., "Mixture-proportioning of high-performance concrete", Cement and Concrete Research, v. 32, n. 11, pp. 1699-1704, 2002.

[17] AIQIN, W., CHENGZHI, Z., NINGSHENG, Z., "Study of the influence of the particle size distribution on the properties of cement", Cement and Concrete Research, v. 27, n. 5, pp. 685-695, 1997.

[18] FUNK, J. E., DINGER, D., Predictive process control of crowded particulate suspensions: applied to ceramic manufacturing. New York, Springer Science \& Business Media, 1994.

[19] OLIVEIRA, C. O., MACIEL, G. F., CASTRO, A. L., et al., "Impacto do conceito de empacotamento de partículas na dosagem de concretos de alto desempenho", Matéria (Rio de Janeiro), [s.1.], v. 23, n. 1, 5 mar. 2018.

[20] VANDERLEI, R. D., Análise experimental do concreto de pós reativos: dosagem e propriedades mecâ- 
nicas, Tese de D.Sc., Universidade de São Paulo, São Carlos, SP, Brasil, 2004.

[21] ASSOCIAÇÃO BRASILEIRA DE NORMAS TÉCNICAS.,NBR 15900-1: Água para amassamento do concreto. Rio de Janeiro, 2009.

[22] ASSOCIAÇÃO BRASILEIRA DE NORMAS TÉCNICAS.,NBR NM 45: Agregados - Determinação da massa unitária e do volume de vazios. Rio de Janeiro, 2006.

[23] ASSOCIAÇÃO BRASILEIRA DE NORMAS TÉCNICAS.,NBR 9778: Argamassa e concreto endurecidos - Determinação da absorção de água, índice de vazios e massa específica. Rio de Janeiro, 2005.

[24] ASSOCIAÇÃO BRASILEIRA DE NORMAS TÉCNICAS.,NBR 5739: Concreto - Ensaio de compressão de corpos de prova cilíndricos. Rio de Janeiro, 2007.

[25] KUMAR, S., SANTHANAM, M. "Particle packing theories and their application in concrete mixture proportioning: A review.” Indian Concrete Journal, v. 77, n. 9, pp. 1324-1331, 2003.

[26] LENZ, L. A., "Avaliação da influência do empacotamento de partículas do esqueleto granular no módulo de elasticidade de concretos convencionais", Dissertação de M.Sc., Universidade Federal do Paraná, Curitiba, PR, Brasil, 2016.

[27] LONDERO, C. "Dosagem de concreto ecológico com base em empacotamento de partículas", Dissertação de M.Sc., Universidade Federal do Paraná, Curitiba, PR, Brasil, 2016.

[28] HERMANN, A., Empacotamento de agregados reciclados para concretos vibrocompactos, Dissertação de M.Sc., Universidade Tecnológica do Paraná, Curitiba, PR, Brasil, 2016.

[29] REBMANN, M. S., "Robustez de concretos com baixo consumo de cimento Portland: desvios no proporcionamento e variabilidade granulométrica e morfológica dos agregados", Tese de D.Sc., Universidade de São Paulo, São Paulo, SP, Brasil, 2016.

[30] BATTAGIN, A. F., “Cimento Portland”. In: ISAIA, G.C. Concreto: Ciência e Tecnologia. São Paulo: Ipsis, v.1, pp. 185-232, 2011.

[31] HELENE, P. R. L., "La Agressividad del Medio y la Durabilidad del Hormigón”, Hormigón, AATH. n. 10, pp. 25-35, ago. 1983.

[32] INTERNATIONAL TUNNELLING ASSOCIATION., "Shotcrete for rock support: a summary reportof the state of the art in 15 countries", Tunneling and Underground Space Techonology. v.8, n.4, pp. 441-470, 1993.

[33] LEVY, S. M., "Contribuição ao estudo da durabilidade de concretos, produzidos com resíduos de concreto e alvenaria”, Tese de D.Sc., Universidade de São Paulo, São Carlos, SP, Brasil, 2001.

[34] LOPES, H. M. T., "Aplicação do conceito de empacotamento de partículas na otimização de dosagem de concretos de cimento Portland", Dissertação de M.Sc., Escola de Engenharia de São Carlos, Universidade de São Paulo, São Carlos, SP, Brasil, 2019.

ORCID

Herbert Medeiros Torres Lopes Ana Carolina Corsi Peçanha Alessandra Lorenzetti de Castro https://orcid.org/0000-0003-2850-9127

https://orcid.org/0000-0002-0321-865X

https://orcid.org/0000-0002-7248-7327 